\title{
A cultura na organização hospitalar e as políticas culturais de coordenação de comunicação e aprendizagem
}

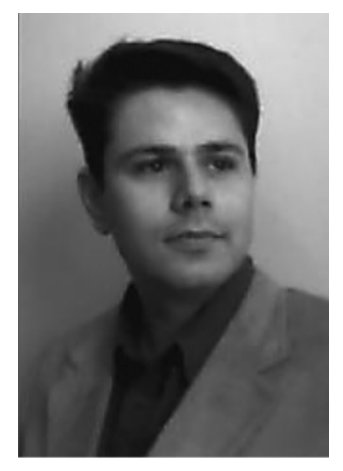

\section{Elói Martins Senhoras}

Instituto de Geociências da Universidade Estadual de Campinas (Unicamp), Campinas, Brasil

eloi@ige.unicamp.br

\section{Resumo}

A importância da cultura por sua característica estratégica dual, enquanto processo e produto de interações, é estudada no presente artigo a partir de uma ótica de gerenciamento e planejamento das organizações hospitalares. As mudanças culturais dentro de um hospital são analisadas, por meio de uma revisão de estudos sobre teorias e práticas nas organizações de saúde, como relações intermediadas por atores em um sistema cultural, que diante da introdução de mecanismos de envolvimento e comunicação reagem mediante mecanismos de aprendizagem. Com essa discussão, argumentos são fornecidos para a garantia de pluralidade e o aprofundamento do debate sobre os caminhos administrativos de coordenação para a eficiência institucional, ao sugerir a criação de mecanismos de comunicação para a construção de incentivos na aprendizagem organizacional e a instrumentalização de critérios simples de análise e desvendamento das culturas de uma organização hospitalar.

\section{Palavras-chave}

Administração hospitalar, cultura, hospital

\section{Introdução}

"A era do empirismo na gestão hospitalar está com seus dias contados. As ferramentas administrativas e financeiras são cada vez mais necessárias."

(R. R. Baumgartner)

O exame da realidade de um hospital revela uma das estruturas mais complexas dentre as que participam da sociedade moderna. Esse argumento é recorrente na área de saúde, levando à percepção de que há especificidades incontornáveis do setor. A razão desse fato é que o hospital, ao longo da história, foi conduzido ao desempenho de diferentes funções, cada vez mais complexas: recuperar, manter e incrementar os padrões de saúde de seres humanos. Essas funções demandam um conjunto altamente divergente e complexo de atividades, tais como a realização de atendimentos, exames, diagnósticos e tratamentos, o planejamento e execução de internações, intervenções cirúrgicas e outros procedimentos.

Para responder às suas diferentes funções, um hospital estrutura-se, por um lado, através de políticas direcionadas, com sentido de cima para baixo, de formação de setores encarregados de atividades bem caracterizadas e, por outro lado, pelo desenvolvimento relacional de uma cultura própria. 
A resultante é a constituição de uma estrutura de marcante complexidade e conflitos, que tem por objetivo o trabalho integrado de seu corpo organizacional na prestação dos serviços de saúde, mas é marcada por uma cultura relacionada à pulverização do poder e à disputa de espaços.

Como alguns dos setores desenvolvem tarefas tão características, que fora do hospital têm freqüentemente vida autônoma, a organização hospitalar torna-se o somatório de hotel, lavanderia, farmácia, escola, centro comunitário, além de centro de atendimento curativo e preventivo.

Diante da dialética organizacional entre a ideal integração para a prestação dos serviços de saúde e a real fragmentação hierarquizada do poder, os hospitais são clássicos exemplos do que MINTZBERG (1994) chama de organizações profissionais, cuja análise demanda motivações, incentivos e cuidados especiais, que são mecanismos de orientação e coordenação que subsidiam as estratégias de decisões gerenciais e administrativas, e se mostram como espaços culturais consideráveis de ajustamentos mútuos de motivações e de compatibilização de interesses.

A caracterização funcional de uma organização hospitalar faz com que ela seja considerada um sistema social aberto, onde estão atuando outros subsistemas técnicos representados pelas especializações dos conhecimentos e habilidades de profissionais como médicos, enfermeiros, psicólogos, nutricionistas entre outros. Em conseqüência, nenhuma pessoa ou grupo é responsável completamente pelo sucesso ou pela qualidade da experiência completa do paciente, uma vez que os profissionais são responsáveis por parte do processo, não havendo uma prestação de contas de todo o ciclo.

Segundo MARINHO (2001), os hospitais são organizações profissionais, que, para tudo funcionar, dependem da capacitação e do conhecimento de seus executores; portanto, os seus resultados não podem ser facilmente medidos ou padronizados, uma vez que dependem fortemente da relação profissional/usuário.

Os hospitais são típicas organizações prestadoras de serviços, de grande utilidade e importância para a comunidade em geral. Além de algumas pessoas terem como trabalho o cotidiano hospitalar, é lá que muitas pessoas buscam ajuda nos momentos fundamentais - e também os mais difíceis - de suas vidas.

Nessas organizações, o trabalho é marcadamente complexo, compreendendo grupos profissionais de diferentes capacitação e formação, mas que estão organizados, predominantemente, em torno de uma base hierárquica composta de especialidades e por especialistas em setores de operação médica, técnica e administrativa.

O trabalho nos hospitais constitui uma prática concreta, em que as mais variadas relações se estabelecem sob diferentes ângulos, por um lado através das relações médico-paciente que focam o tratamento, a prevenção e o atendimento à saúde, e, por outro lado, através das relações de trabalho que permeiam as hierarquias e os ethos de trabalho, sob a ótica humanista, e os modos de organização da produção e consumo da saúde dentro do hospital sob a ótica gerencial.
As estruturas hospitalares tradicionais geralmente se caracterizam como pró-cíclicas, pois funcionam muito bem quando as variações do ambiente externo não produzem impacto significante sobre as rotinas organizacionais, embora em um ambiente mutável e que geralmente exige constantes adaptações esse estilo de estrutura não se mostre eficiente, já que centraliza ações e não estimula a cooperação nem o aprendizado (ABDALA et al., 2006).

Questões técnicas e práticas de gerência administrativa têm sido um dos pontos mais criticados nas organizações hospitalares devido ao fato de serem consideradas organizações complexas, que envolvem uma série de processos e atividades paralelas à atividade-fim do hospital, que é o cuidado ao paciente (LIMA-GONÇALVES, 2002).

As diferenças entre as organizações hospitalares e os outros tipos de organizações são também um ponto importante para a compreensão dessas organizações e dos fenômenos que nelas ocorrem. Os fatores que mais distinguem as organizações hospitalares de outros ramos de negócio são: a) a dificuldade de definir e mensurar o produto hospitalar; b) a freqüente existência de dupla autoridade gerando conflitos; c) a preocupação dos médicos com a profissão e não com a organização, d) a alta variabilidade e complexidade do trabalho, extremamente especializado e dependente de diferentes grupos profissionais; e) dado o acentuado dinamismo tecnológico, o setor é essencialmente de trabalho intensivo; e) muitas das inovações tecnológicas implicam não mudanças no método de prestação de um dado serviço, mas a introdução de um novo serviço que se soma aos anteriores e exige pessoal adicional para sua prestação; g) a produtividade do trabalho depende, sobretudo, de uma combinação adequada entre os vários tipos de profissionais; $h$ ) ao pessoal de nível superior, e, principalmente, aos médicos, são atribuídas as funções mais complexas, envolvendo a gerência administrativa e o comando técnico do trabalho dos auxiliares, além de sua normalização e supervisão; i) as funções mais simples ficam com o pessoal auxiliar, que as executam em cumprimento das normas de trabalho; j) em algumas áreas, as forças produtivas da ciência e da tecnologia atuam no sentido de elevar a produtividade do processo de trabalho, mas limitados a uns poucos procedimentos terapêuticos e diagnósticos (RODRIGUES FILHO, 1990).

Somente as organizações de saúde possuem todas estas características ao mesmo tempo, derivando deste fato o desafio de integrar o todo organizacional diante da divisão e especialização do trabalho que produz vasta segmentação interna.

\section{A cultura inserida no novo paradigma da administração hospitalar}

A noção de cultura organizacional é um importante conceito a ser usado na administração hospitalar, pois permite à organização de saúde encontrar a sua identidade coletiva, possibilitando a criação de mecanismos eficientes de comunicação para fornecer a seus membros 
as significações que eles precisam para contribuir com a performance organizacional.

A discussão sobre a cultura hospitalar pode ajudar as instituições de saúde, como elemento estratégico, a pensarem sobre a sua administração, pois a preocupação com a cultura nasce associada tanto às necessidades de aperfeiçoar o desenvolvimento dos processos em um hospital, quanto das relações de poder e o confronto de interesses dentro dessa organização.

A formação cultural é uma preocupação contemporânea, bem viva nos tempos atuais, pois busca entender os muitos caminhos que conduzem os grupos humanos às suas relações presentes no desenvolvimento das organizações, que estão marcadas por contratos e conflitos entre os modos diferentes de organizar a vida social, de se apropriar dos recursos e transformá-los.

"O processo de formação da cultura organizacional é idêntico à formação de grupos, que compartilham das crenças, pensamentos, sentimentos e valores, que resultam de experiências e do aprendizado coletivo. Isto significa que, sem a formação de grupos, não haverá cultura e que estes grupos, para justificarem suas existências, tornam-se focos de formação de subculturas." (MACEDO, 1996)

Qualquer agrupamento humano, submetido a um certo grau de isolamento e sob ação de determinadas influências, desenvolve, ao longo do tempo, algumas características comportamentais, em termos de hierarquização de valores e modos de expressão que o diferenciarão de outros grupos, estabelecendo-se assim uma espécie de identidade coletiva, chamada cultura. (Quadro 1)

\section{Quadro 1 - Origens da formação da cultura organizacional}

\begin{tabular}{|l|l|}
\hline $\begin{array}{l}\text { Única e } \\
\text { via consenso }\end{array}$ & $\begin{array}{l}\text { A cultura é resultado dos atributos e de } \\
\text { ações de consenso e de harmonia entre } \\
\text { os indivíduos. Nem todos os membros } \\
\text { participam da formação, pois a cultura } \\
\text { pode ser legitimada pela imposição e } \\
\text { aceitação. }\end{array}$ \\
\hline $\begin{array}{l}\text { Múltipla e } \\
\text { via Conflitos }\end{array}$ & $\begin{array}{l}\text { Todos os membros de uma organização } \\
\text { participam da criação da sua cultura, } \\
\text { e ela é o resultado da sedimentação } \\
\text { de uma história de conflitos e de uma } \\
\text { variedade de subculturas. }\end{array}$ \\
\hline
\end{tabular}

Fonte: Elaboração própria

A emergência de uma nova cultura em um ambiente hospitalar pode ser entendida duplamente como produto e processo que se difunde por meio de uma institucionalização formal e informal.

A temática da cultura toma importância nas organizações de saúde quando mudanças e novas capabilities de comunicação são exigidas na estrutura e no conjunto de funcionários devido à identificação de padrões culturais deletérios à eficiência organizacional.

Verifica-se que muitas vezes na prática hospitalar, entretanto, as mudanças culturais e as novas capacitações de comunicação e aprendizagem não são, necessariamen- te, pontos de consenso ou aceitação, pois representam uma ameaça aos valores e práticas profissionais dos funcionários e aos próprios padrões culturais estabelecidos no trabalho. Para se protegerem dessa ameaça, em muitos casos, os médicos e enfermeiros desenvolvem resistências às mudanças em razão do medo do que é desconhecido, preferindo, assim, continuar com seus próprios canais de comunicação e padrões de conduta, a fim de realizarem suas atividades como sempre fizeram (MAGALHÃES et al., 2006).

"As mudanças geram incertezas, transformam as relações de poder, mudam a estrutura das forças que sustentam o status quo e obrigam a procurar novas formas para a resolução dos conflitos que advêm com a nova era. Há de se perguntar se realmente a alta administração está disposta a enfrentar a mudança indo à raiz dos problemas, pois isso implica, muitas vezes, em perda de poder ou em redistribuição do mesmo." (MACHADO et al., 2004)

No intuito de incrementar a eficiência das organizações hospitalares, os gestores devem lançar mão de estratégias e mecanismos que permitam a identificação de subculturas existentes, e, através de mecanismos de comunicação, incentivar a participação e integração dos atores na busca de uma nova cultura e de um novo aprendizado. (Quadro 2)

\section{Quadro 2 - Óticas de análise das culturas nas organizações}

\begin{tabular}{|l|l|}
\hline Linha de trabalho & \multicolumn{1}{|c|}{ Conceito de cultura } \\
\hline Cultura corporativa & $\begin{array}{l}\text { A cultura funciona como um me- } \\
\text { canismo regulatório adaptativo. Ela } \\
\text { permite a articulação dos indivíduos } \\
\text { na organização. }\end{array}$ \\
\hline $\begin{array}{l}\text { Cognição } \\
\text { organizacional }\end{array}$ & $\begin{array}{l}\text { A cultura é um sistema de cognições } \\
\text { partilhadas. A mente humana gera a } \\
\text { cultura através de um número limitado } \\
\text { de regras. }\end{array}$ \\
\hline $\begin{array}{l}\text { Simbolismo } \\
\text { organizacional }\end{array}$ & $\begin{array}{l}\text { A cultura é um sistema de símbolos e } \\
\text { significados partilhados. A ação simbó- } \\
\text { lica necessita ser interpretada, lida ou } \\
\text { decifrada a fim de ser entendida. }\end{array}$ \\
\hline $\begin{array}{l}\text { Processos } \\
\text { inconscientes e } \\
\text { organização }\end{array}$ & $\begin{array}{l}\text { A cultura é uma projeção da infra- } \\
\text { estrutura universal e inconsciente da } \\
\text { mente. }\end{array}$ \\
\hline
\end{tabular}

Fonte: Elaboração própria. Adaptação baseada em Paiva e Sampaio (2003).

Cada realidade cultural tem sua lógica interna, a qual se deve procurar conhecer para que façam sentido as suas práticas, costumes, concepções e as transformações pelas quais passam. É preciso relacionar a variedade de procedimentos culturais com os contextos em que são produzidos e os impactos que eles causam.

Nota-se, porém, que o convite a que se considere cada cultura em particular não pode ser dissociado da necessidade de se considerar as relações entre as culturas. $\mathrm{Na}$ verdade, se a compreensão da cultura exige que 
se pense na diversidade de funcionários do hospital, é porque eles estão em interação.

Mais importante ainda é observar que o destino de cada agrupamento é marcado pelas maneiras de organizar e transformar a vida em sociedade e de superar os conflitos de interesse e as tensões geradas na vida social.

É importante considerar a diversidade cultural interna à sociedade hospitalar; isso é de fato essencial para compreendermos melhor a instituição, mesmo porque essa diversidade não é feita só de idéias; ela está também relacionada com as maneiras de atuar na vida social e o impacto financeiro causado por determinadas alocações.

Apesar dessa variabilidade nas formas de organização social, são notórias algumas tendências dominantes em um hospital, como a formação de poderosos núcleos com instituições políticas centralizadas. A formação desses núcleos duros, ou core sets, tem origem nos processos de sedimentação de políticas administrativas direcionadas desde a fundação da organização de saúde, o que tende a conferir uma especificidade na construção do policy making administrativo em um hospital por meio de uma "burocracia" hierarquizada de experts, que se institucionaliza ao longo do tempo por caminhos culturais relacionais que reafirmam e legitimam a própria assimetria de poder na estrutura diária de trabalho.

Os esforços para colocar todas as culturas de uma instituição de saúde num único e rígido esquema de etapas não são, entretanto, eficientes, embora se manifeste presente uma hierarquia nítida de interesses, por onde prevalece o direcionamento da formação das culturas. Nesse sentido, os critérios culturais existentes no interior da organização hospitalar acabam por justificar o entendimento de que os hospitais são organizações profissionais estratificadas por relações de dominação, onde o exercício tradicional do poder se manifesta pela posição técnica de cada funcionário.

A investigação sobre as características e traços das culturas em um hospital revela que estas não são algo acabado, fechado ou estagnado, mas antes, são dinâmicas e moldadas pelas relações de poder. De fato, a principal vantagem de estudá-las é por contribuírem para o entendimento do policy making administrativo e dos processos de comunicação e aprendizagem por que passa um hospital.

\section{A correlação entre cultura organizacio- nal hospitalar e o seu desempenho}

Entre os fatores que explicam o baixo desempenho das organizações de saúde são tradicionalmente identificados duas ordens de problemas: em primeiro lugar, em nível institucional, está relacionado às questões de financiamento, de desenho institucional e o sistema de prestação de contas dos profissionais de saúde; e em segundo, em nível sistêmico, estão ligados aos argumentos de crise dos modelos assistenciais em saúde no mundo.

A hipótese sugerida pelo artigo é que as variáveis culturais institucionalizadas têm peso significativo na determinação da baixa eficiência hospitalar, não desprezadas as influências anteriores de ordem institucional e sistêmica, que contribuem na definição relacional da cultura organizacional.

Tradicionalmente, a estrutura física e tecnológica e a estrutura econômico-política de financiamento têm sido os componentes considerados mais importantes para a performance das organizações hospitalares; entretanto, os processos simbólicos ligados à pratica institucional dentro de um hospital, ou seja, à cultura organizacional, podem ter um papel significante.

Diz BARLEY (1986) que a estrutura cultural de uma organização influencia o desempenho dos profissionais e estes influenciam também a estrutura. Dentro desse enfoque, sabe-se que é necessário resgatar o saber dos profissionais que desempenham suas funções no setor de serviços de saúde e possibilitar que disponham de uma estrutura de trabalho adequada, flexível, para atender às suas necessidades.

Existe, ainda, a necessidade de encontrar as causas das falhas dos processos de produção hospitalares, buscando mecanismos de comunicação para a prevenção das mesmas e para melhorar a alocação de recursos para esses serviços e, conseqüentemente, reduzir custos (Figura 1).

\section{Figura 1 - Mapa de problemas em um ambiente hospitalar}

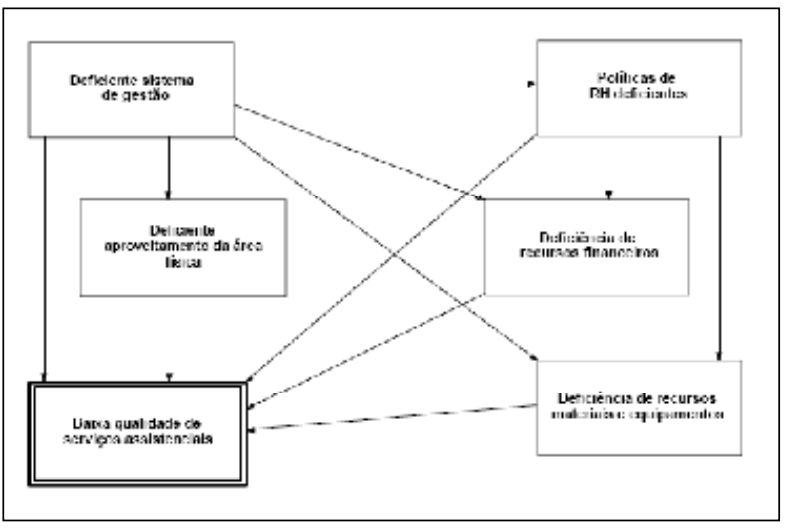

Fonte: LIMA-GONÇALVES (2002).

Segundo LANZER et al. (1995), os processos organizacionais são afetados por vários fatores, e cada fator é ainda influenciado por outros tantos. O mesmo acontece no ambiente interno da organização, há influência de uma multiplicidade de fatores sobre os processos produtivos, o que torna os processos variáveis.

Essa variabilidade merece monitoração e identificação de pontos de controle ou gargalos, uma vez que existe uma iminente possibilidade de fatores culturais estarem atuando. No setor saúde esse aspecto merece uma atenção especial, pois, como sugere SANTOS (1995), talvez em nenhuma outra área da atividade humana a conceituação da qualidade e sua aplicação seja tão importante, uma vez que a falha de procedimentos traz conseqüências sérias, expondo ao risco o usuário. 
O primeiro problema cultural a ser discutido são as barreiras de comunicação nas organizações de saúde, que têm tornado difícil aos recursos humanos se debruçarem sobre seus resultados para avaliá-los e posteriormente discuti-los, pois partem da premissa de que sempre fazem o melhor que pode ser feito. Este problema cultural tem a ver com algum grau de autoritarismo e com aspectos de corporativismo, pois assume a assimetria na relação equipe/paciente, ou, mais freqüentemente, médico/paciente (CARAPINHEIRO, 1993).

A expressão "máfia de branco" não é nova e esconde falhas, onde se espera dos profissionais que se protejam ou pelo menos não denunciem; e, por outro lado, justifica que se tomem decisões em nome dos pacientes, que se privilegiem algumas categorias profissionais em detrimento de outras e que se assuma os hospitais (pelo menos alguns deles) como organizações médicas, em detrimento do conceito mais amplo, de organizações de saúde. Isto de alguma maneira explica que há hospitais em que se consegue modificar a cultura de todas as áreas com maior ou menor facilidade, por vezes sendo necessário um refluxo das iniciativas (PICCHIAI, 1998).

Esta mesma cultura do corporativismo faz com que se justifiquem algumas dificuldades presentes na gestão em saúde, uma vez que a autonomia na liderança do grupo profissional nuclear e a presença ativa dos profissionais de base operacional, em uma situação de problemas de comunicação, podem criar uma série de atritos que dificultam as ações de coordenação.

De fato, observa-se que pelo menos duas áreas dos hospitais usualmente desenham seus próprios modelos de gestão e de avaliação, não se curvando aos ditames da organização (a enfermagem e o corpo médico), o que conseqüentemente causa ineficiências na alocação de recursos, ampliando um gap financeiro ou de custos entre planejado e efetivo.

As instâncias superiores da hierarquia representam estruturas administrativas nas quais os profissionais influenciam, por força da organização descentralizada e motivados pelo interesse de adquirir controle coletivo, as decisões administrativas que os afetam. Ademais, existem nessas organizações recursos comuns significativos, incluindo atividades de apoio, que justificam o movimento da base para o topo da hierarquia, razão por que a organização profissional hospitalar já teria sido denominada pirâmide invertida.

A cultura da verticalização nas relações profissionais manifesta-se pela existência de diferenças na valorização social oferecida aos trabalhadores e pela centralização das decisões que interferem no processo organizativo, representação de práxis autoritária.

A falta de metodologias de avaliação hospitalar dificulta o desenvolvimento do perfil de cada hospital, principalmente a visualização de todas as suas deficiências e os danos que decorrem destas aos pacientes e profissionais. O problema está, na verdade, na ineficiência do próprio processo de avaliação hospitalar, pela falta de instrumentos e normas, e na cultura que se sedimenta na organização, permitindo comportamentos que tradicio- nalmente são conhecidos na literatura econômica como oportunistas e conspiram contra a eficiência do sistema.

Todos esses problemas culturais impactam de uma maneira ou de outra segundo uma correlação com o desempenho institucional e financeiro das instituições de saúde, seja devido à má alocação de recursos, seja por ineficiências oriundas da assimetria de informações ou de comportamentos oportunistas, que dificultam as ações de coordenação, correspondendo a maiores gastos.

A identificação dos incentivos culturais de modelagem das organizações hospitalares e do comportamento dos profissionais é um insumo-chave para a formulação de políticas internas de mudança cultural e promoção de novas instituições que se ponham em prática. Isso é importante aos funcionários diretamente ligados à administração hospitalar e aos diretores de hospital, não só porque existe uma percepção generalizada de que determinadas configurações de cultura organizacional estão afetando sensivelmente o desempenho hospitalar, mas porque também se relacionam de maneira sinérgica com outras variáveis institucionais e financeiras.

\section{Políticas culturais de gestão e planejamento}

As organizações de saúde, identificadas na tipologia de MINTZBERG (1982) como organizações profissionais, ainda são em grande número gerenciadas por profissionais da área da saúde, com pouco ou nenhum conhecimento administrativo. Este fato tem acarretado grandes dificuldades à sobrevivência dessas instituições.

No dia-a-dia, a imprensa tem divulgado as condições dos hospitais públicos e privados nas diferentes regiões brasileiras: falta de leitos, superlotação, desperdício, sucateamento dos equipamentos, falta de recursos humanos qualificados, descontentamento da clientela interna e externa, entre tantos outros.

Para que uma organização hospitalar cumpra com efetividade sua missão, é imprescindível que suas ações decorram de um planejamento organizado e permanente, baseado nas políticas e diretrizes às quais a organização se vincula, no conhecimento das expectativas dos funcionários e levando em conta as condições e os meios de que dispõe.

É preciso abandonar a cultura do planejamento ocasional, para adotar o planejamento como um exercício permanente e sistemático. Os exercícios de planejamento de ocasião podem até produzir bons resultados, mas, inexistindo uma consciência sobre a importância de se estabelecerem rumos precisos para a instituição, os projetos acabam por definhar, sem nunca resultarem em ações de melhoria em relação ao futuro desejado para a organização.

Um planejamento que confira consistência à atuação da instituição deve iniciar com as definições culturais da organização hospitalar e fechar o seu ciclo com a definição de metas claras e específicas que traduzam o conjunto cultural de aspirações institucionais em ações práticas, que lhe permitirão caminhar, de fato, na direção 
desejada. A partir de um primeiro ciclo de definições de valores, crenças, ritos, tabus, mitos, normas, sistemas de comunicação formal e informal e produtos ou artefatos visíveis é preciso rever periodicamente o ambiente, as ameaças e as oportunidades que se apresentam, de forma a poder prever situações que possam vir a interferir no que foi planejado, o que possibilitará a revisão tanto de estratégias, quanto de ações (Quadro 3).

\section{Quadro 3 - Elementos de composição da cultura em organizações hospitalares}

\begin{tabular}{|c|c|}
\hline Valores & $\begin{array}{l}\text { Correspondem a tudo aquilo que a } \\
\text { organização considera importante para } \\
\text { preservar, realizar e manter a imagem e } \\
\text { o nível do sucesso desejado, como por } \\
\text { exemplo, a importância da satisfação } \\
\text { dos pacientes. }\end{array}$ \\
\hline Crenças & $\begin{array}{l}\text { Podem ser sentidas através do compor- } \\
\text { tamento das pessoas e estão ligadas } \\
\text { à busca de eficiência. Os ritos são as } \\
\text { formas como são praticadas e perse- } \\
\text { guidas as crenças e metas planejadas } \\
\text { no dia-a-dia. }\end{array}$ \\
\hline Tabus & $\begin{array}{l}\text { Referem-se às proibições impostas aos } \\
\text { membros da organização e às orienta- } \\
\text { ções e fatos tidos como inquestionáveis. } \\
\text { O fato de que os médicos devem receber } \\
\text { salário superior ao dos subrodinados } \\
\text { constitui um exemplo. }\end{array}$ \\
\hline $\begin{array}{l}\text { Mitos organiza- } \\
\text { cionais }\end{array}$ & $\begin{array}{l}\text { São gerados pela cultura existente e cor- } \\
\text { respondem a expressões conscientes da } \\
\text { mesma. Guardam relações com as crenças } \\
\text { e valores professados, pois são cristalizações } \\
\text { dos mesmos ao longo do tempo. }\end{array}$ \\
\hline Normas & $\begin{array}{l}\text { São regras escritas ou não que direcio- } \\
\text { nam a forma como as pessoas devem } \\
\text { proceder para que a organização alcance } \\
\text { os seus objetivos, sendo aceitas ou não, } \\
\text { dependendo da coerência em relação às } \\
\text { expectativas e aspirações. }\end{array}$ \\
\hline $\begin{array}{l}\text { Comunicação } \\
\text { formal }\end{array}$ & $\begin{array}{l}\text { É a comunicação sistemática entre a orga- } \\
\text { nização e o ambiente externo e interno, } \\
\text { feita através de comunicados, entrevistas, } \\
\text { memorandos, ofícios, textos etc. }\end{array}$ \\
\hline $\begin{array}{l}\text { Comunicação } \\
\text { informal }\end{array}$ & $\begin{array}{l}\text { É a comunicação assistemática que } \\
\text { não está sujeita a normas ou controles, } \\
\text { ocorrendo por meio de relações interpes- } \\
\text { soais de forma subjetiva e sem controles } \\
\text { externos. }\end{array}$ \\
\hline $\begin{array}{l}\text { Produtos ou arte- } \\
\text { fatos visíveis }\end{array}$ & $\begin{array}{l}\text { Referem-se ao ambiente construído da } \\
\text { organização hospitalar, aos comporta- } \\
\text { mentos e resultados visíveis do staff de } \\
\text { trabalho, documentos públicos, que, } \\
\text { embora sejam visíveis, são de difícil } \\
\text { interpretação }\end{array}$ \\
\hline
\end{tabular}

Fonte: Elaboração própria. Baseada em TAVARES (1996).

As organizações hospitalares e seus gerentes sofrem o impacto das transformações. A gerência desloca-se da prática de simples técnicas administrativas de controle para a incorporação de novas habilidades e atitudes na participação descentralizada. Estratégia, capacidade criativa e de inovação, habilidade de comunicação, de relacionamento e de negociação passam a ser atributos desses profissionais (CHERUBIN, 1997).

A importância dessa alta direção na definição do funcionamento, da missão e dos objetivos em um hospital continua a fazer parte inerente dos processos de gestão e planejamento organizacional, o que descaracteriza um possível ponto de paradoxo entre a definição estratégica vertical de politicas administrativas e o compartilhamento horizontal de informações e de espaços de participação, uma vez que o gerenciamento e o planejamento hospitalar têm que incorporar simultaneamente as horizontalidades e verticalidades relacionais do dia-a-dia do trabalho e, portanto, a administração de relações de cultura, poder e participação.

Para TODESCATI (1996), a capacidade inerente da organização de aprender continuamente sobre seu próprio ambiente, a fim de produzir reações apropriadas e mobilizar recursos para competir, acenam com a necessidade de se administrar uma cultura organizacional global. Isto é, uma visão multidimensional, que implica mudanças na participação e na comunicação, pois organizações flexíveis e pessoas abertas são fatores primordiais para o sucesso da implantação dessas mudanças. Entende-se, então, que as instituições que buscam aperfeiçoamento não devem estar restritas ao processo/produto e à satisfação do cliente externo, mas contemplar também a qualidade da gerência, a qualidade de vida da sua força de trabalho, na comunidade onde se instala, sem perder de vista os ideais do bem comum.

Para que as ações resultantes de um planejamento se realizem, concretizando a implementação de uma "gestão cultural", é imprescindível que cada servidor tenha plena consciência da missão institucional e pleno conhecimento dos resultados globais desejados, de forma a poder identificar qual é o espaço de sua contribuição individual para que esses resultados sejam alcançados.

Simultaneamente à comunicação e ao planejamento interno, existe um processo de conscientização, diálogo e negociações obrigatório com os canais de poder ou influência que estão propriamente fora dos hospitais, os Conselhos Profissionais, que impactam diretamente as ações diárias em uma organização de saúde por meio dos interesses de classe e de padrões profissionais de conduta individuais a cada profissão, o que pode acabar pulverizando uma possível missão coletiva de um hospital devido aos diferentes objetivos que atravessam a missão da organização, por vezes a não considerá-la como algo do coletivo.

Dois fatores críticos para garantir o sucesso e a continuidade de uma efetivação cultural em uma instituição de saúde são a valorização dos funcionários e a comunicação, que devem ser garantidas não só pela remuneração, mas, sobretudo, pelo compartilhamento das informações, por investimento permanente em capacitação e pela disponibilidade de um espaço de participação, integrando-os ao processo de planejamento, no que diz respeito à elaboração de metas, definição de indicadores e concepção dos planos operacionais. 
A centralidade da alta administração se faz não mais pela exclusividade na definição de variáveis para o funcionamento de um hospital, mas, antes, pela sua capacidade de coordenar a aprendizagem cultural da organização por meio de espaços de participação e comunicação dos funcionários de base, uma vez que a liderança nessas áreas promove um aproveitamento mais eficiente do gerenciamento no contexto hospitalar.

Em primeiro lugar, um indivíduo compromete-se com aquilo que conhece, e o comprometimento será tão intenso quanto maior for sua participação na definição e no planejamento do que se pretende atingir. Assim, uma vez definidas pela alta administração da instituição as questões estratégicas, como missão, visão de futuro e objetivos de desempenho financeiro, por meio de seu aprendizado horizontal junto aos funcionários, é sua responsabilidade compartilhar essas informações com funcionários, para que todos tenham plena consciência do rumo a ser seguido e o seu papel nessa definição estratégica. Ademais, os objetivos institucionais precisam ser traduzidos em metas para cada unidade administrativa da organização hospitalar, de forma a que toda a instituição participe da construção dos resultados desejados.

Em segundo lugar, ao ser evidenciado que o sucesso das organizações hospitalares depende em grande parte dos recursos humanos, torna-se necessária uma política de construção de um ambiente com fácil comunicação, que encoraje e torne possível às pessoas se comportarem de maneira a contribuir para um eficiente desempenho individual. E também da organização, uma vez que a fragilidade dos sistemas de informação (médico e administrativo) é muito mais um problema cultural institucionalizado que uma especificidade qualquer nos hospitais, pois constata-se que os produtores dos fatos de onde se retiram os dados que se tornam informações estão muito distantes, nas estruturas organizacional, física e hierárquica, daqueles que trabalham os dados e os transformam em informações.

Nesses dois contextos, a demanda por soluções eficazes a custos aceitáveis exige das organizações cada vez mais criatividade, manipulação e integração de conhecimentos multidisciplinares. SENGE (1992) afirma que o aumento da complexidade e da dinâmica dos trabalhos induz à necessidade de associar o trabalho à aprendizagem. Em outras palavras, a adoção da aprendizagem nas organizações tem condições de adaptá-las a um ambiente complexo, turbulento e competitivo.

É primordial ressaltar que o sucesso da organização de aprendizagem é dependente da integração sistêmica das pessoas por meio da criação de canais confiáveis de comunicação. Possivelmente tal empreendimento pode se basear em uma cultura organizacional adaptativa e norteada pela busca de ajuste ao ambiente.

Segundo KOTTER et al. (1994), culturas adaptativas têm, como um de seus valores essenciais, a profunda consideração pelos clientes e empregados, o que possibilita que tendências sejam apreendidas, e iniciativas sejam tomadas na promoção de mudanças necessárias, ainda que implicando assumir algum risco.
"A literatura trata separadamente as dimensões cultura e aprendizagem, ao contrário do que ocorre na organização. Estas componentes presentes no ambiente organizacional têm a propriedade de permear e compartilhar o mesmo espaço, oferecendo entre si informações que podem modificar as práticas em uso na organização, assim, a cultura organizacional referencia a construção de um conjunto de valores, crenças, símbolo e fatos sociais, consoantes na evolução histórica da organização. A aprendizagem organizacional por sua vez se apresenta como uma clara referência à disseminação de conhecimentos na organização." (PIVETA, 2004).

É fundamental lembrar a importância de ações concretas para a criação de um clima organizacional favorável à cultura adaptativa por meio de canais de comunicação para a aprendizagem, uma vez que esta permite o desenvolvimento de aprendizagem organizacional permeada pelo trabalho em equipes, sendo compatível com as necessidades da organização hospitalar para enfrentar um ambiente mais dinâmico.

\section{Os 3 Cs: Cultura, Comunicação e Coor- denação}

Quando se fala em cultura, se fala em premissas, em crenças existentes nos níveis consciente e inconsciente que direcionam a atitude das pessoas, pois, como a organização é um sistema de atividades ou forças em coordenação consciente, de duas ou mais pessoas, a cultura em uma organização é o conjunto de valores e premissas segundo as quais seus membros tendem a pensar, agir e se relacionar.

$\mathrm{Na}$ medida em que as decisões organizacionais práticas e sensatas forem provenientes de um conjunto de ideais coerentes e integradas às culturas hospitalares, elas têm maior probabilidade de obter êxito a longo prazo, pois há consistência no compartilhamento de comunicação e de valores.

A cultura bem planejada dá mais liberdade ao indivíduo, uma vez que não é preciso dizer a ele o que é ou não importante, haja vista que o funcionário leva como bagagem intrínseca o conjunto de valores aprendidos que deve nortear sua ação.

A comunicação, portanto, é uma pilastra de aprendizagem para a coordenação cultural, de onde decorre a funcionalidade maior ou menor para a diminuição de custos de transação dentro da organização hospitalar.

Quanto mais eficientes os canais de comunicação em um hospital, maior a capacidade de aprendizagem das culturas internas e, portanto, maior é o potencial de amplitude de controle e coordenação sobre a organização, com mais subordinados por chefe e, conseqüentemente, um número menor de níveis hierárquicos.

Um elemento crítico em um hospital é o modelo de comunicação adotado, pois as escolhas adotadas pelo núcleo duro administrativo desempenham um papel importante ou não para a integração interfuncional das atividades realizadas pelos funcionários de base.

O emponderamento dos canais de comunicação representa uma importante experiência de abertura de 
espaços para o diálogo e para o maior comprometimento dos funcionários com as necessidades do paciente e da própria organização hospitalar, pois consiste em uma estratégia de aprendizagem contínua, fundamental para implementar as mudanças necessárias na administração hospitalar.

"Sabendo que a ausência de comunicação ou de troca de informações não gera comprometimento, a comunicação assume, nesse contexto, um importante papel. Ao proporcionar a reunião das partes distintas da organização, ela se faz presente na constituição de relações de responsabilidade, confiança e credibilidade e, principalmente, no planejamento de ações que vislumbram o alinhamento do pensamento do empregado ao do empregador." (SOUZA et al., 2006)

Como muitas vezes a administração tradicional dos hospitais não tem canais bilaterais de comunicação entre o núcleo duro da gestão e planejamento e os funcionários de base, é recorrente o entendimento de que esta forma de gerenciar contribui para o não atendimento das necessidades reais do paciente, por estar muito focado nas necessidades financeiras da organização, gerando conflitos e insatisfações nas equipes médicas e de enfermagem, e em muitas poucas vezes gerando reais situações de redução de custos.

Segundo TREVIZAN et al. (1998), no âmago da nova liderança gerencial está a capacidade de comunicar, o que torna a comunicação fundamental para o exercício da aprendizagem, para a coordenação das atividades grupais e, portanto, para a própria efetivação do processo de gestão e planejamento nos hospitais.

Por um lado, a comunicação é um recurso que permite à liderança do core set administrativo aproximar-se dos funcionários de base com o intuito de compreender as atividades de cada um, compartilhar idéias e visões, apreender as variáveis que funcionam bem e as que não funcionam, bem como criar interdependências para o corte das ineficiências, para a gestão de melhorias contínuas e para o desenvolvimento do trabalho através de equipes.

Por outro lado, o aumento da comunicação no "chão do hospital" tem importância para o aumento da eficiência operacional diante das situações de aprendizagem na relação profissional-paciente, quando há um processo de troca de informações entre os pacientes e os médicos e enfermeiros. O aprendizado a partir da comunicação seria muito mais uma habilidade instrumental adquirida no processo diário dos profissionais de saúde do que propriamente uma proposta explícita na maioria dos cursos de formação vivenciados por eles (ROSSI et al., 2006).

Partindo-se do entendimento de que a comunicação é uma habilidade que tem espaço de ampliação no processo de gestão hospitalar, torna-se importante na formação profissional haver propostas mais explícitas de aprendizagem de comunicação em nível horizontal (relações entre profissionais de base e pacientes) e em nível vertical (relações entre profissionais de base e gerência).

A comunicação em um ambiente integrado por determinada cultura fica extremamente facilitada diante de interlocutores que compartilham valores, idéias e até um jargão particular, tribal. Também na comunicação com o exterior da estrutura deverá ser percebida certa coerência entre as atitudes de diferentes membros da mesma organização.

Em um estudo sobre as formas hierárquicas, as redes de comunicação e as percepções da cultura organizacional, NELSON (2003) identificou que nos hospitais as redes de comunicação têm um impacto mais eficiente no aproveitamento das subculturas a políticas hierárquicas unidirecionais de comando, pois estas últimas, muitas vezes, limitam o impacto da aprendizagem das redes de comunicação e, portanto, a própria transformação cultural em um hospital.

As realidades organizacionais contemporâneas têm procurado cada vez mais liberar a criatividade comunicacional e a inovação através da adoção de medidas que visam o desenvolvimento do potencial e da capacidade das pessoas, ou seja, de seu capital humano. Neste sentido, a cultura da organização hospitalar é capaz de exprimir uma visão que inspire e fortaleça todos na instituição.

É preciso mudar culturas que impactam negativamente no desempenho institucional e financeiro e, para isto, é necessário administrar recursos humanos de forma ampla, com um planejamento adequado ao longo de todo o tempo em que o funcionário fizer parte da organização. É preciso considerar, sobretudo, que estes recursos tão importantes das instituições de saúde sejam não apenas o pessoal que nelas trabalha, mas sim a própria organização.

"A estratégia de mudança cultural exige dos agentes
mobilizadores deste processo, em especial dos gestores,
que atentem para a rapidez do processo, a duração e
a extensão das mudanças. Há necessidade de pessoas
que saibam como conduzir em situações de crises e de
conflitos, saibam se comunicar e que tenham conheci-
mento técnico. Deve ser lembrado que no processo de
implantação da reforma, deve-se gerir os paradoxos: a
estabilidade e a mudança." (MACEDO, 1996)

Diante da constatação de que pouco se pode fazer ou influenciar sobre questões como a limitação de recursos, volume de atividades manuais, pouca previsibilidade e alta taxa de mudança dos procedimentos médicos, a questão da cooperação e, por conseqüência, da coordenação tomam importância crescente para o aumento da produtividade através dos recursos existentes.

Atuar sobre a cultura significa atuar sobre o componente humano da organização - o principal fator no esforço da melhoria da qualidade dos processos. A constância de propósito na coordenação de um esforço contínuo de melhoria só é possível se a preocupação com a qualidade for um dado cultural da organização. Uma cultura moderna, menos hierárquica, mais horizontal, permite a propagação da "voz do cliente" interno (funcionários) e externo (pacientes), isto é, de suas necessidades e aspirações de maneira mais adequada.

BORBA et al. (1998) apontam que os sistemas hospitalares possuem duas alternativas para se adaptarem aos anseios de seus clientes: aumentar a capacidade 
disponível ou aumentar a produtividade do sistema existente.

Mas quais são os mecanismos e ferramentas para atuar na cultura organizacional? É um ponto extremamente controverso. Atuar sobre valores e crenças das pessoas é difícil e pode dar resultados opostos aos esperados. Não obstante, é questão de competência gerencial direcionar o perfil cultural no sentido de municiá-lo de características que levem ao alcance dos mais altos objetivos do sistema.

\section{À guisa de últimas considerações}

Existem características culturais favoráveis à sobrevivência e ao desenvolvimento das instituições de saúde e características desfavoráveis; independendo do caso, o desenvolvimento espontâneo de uma cultura própria afeta o comportamento dos indivíduos e, portanto, o resultado alcançado pelo sistema.

A importância da comunicação em uma organização de saúde reside na sua capacidade de direcionar o aprendizado organizacional dentro do sistema hospitalar, ao corroborar para a mudança de forma na cultura, uma vez que todo grupo humano submetido a influências específicas e a certo grau de isolamento tende a desenvolver uma série de características comportamentais e de hierarquização de valores que o caracterizará.

"A mudança de cultura organizacional é um processo difícil e lento, mas as modificações radicais, como as decorrentes do processo de reforma, facilitam o nascimento de uma nova cultura. [...] Assim, a cultura pode ser modificada através a avaliação de normas, de comportamentos, nos momentos de crise e de conflitos e o gestor, pelo seu poder dentro da organização, é um agente que pode influenciar o surgimento de uma nova cultura. A cultura organizacional pode então ser gerenciada e modificada através do aprendizado da organização, dependendo, no entanto, a sua velocidade e cristalização, das circunstâncias e momentos e, principalmente, da definição clara da vontade da organização em definir sua filosofia, sem que isto signifique mecanismo de dominação." (MACEDO, 1996)

Diante da escassez de mecanismos que permitam às organizações hospitalares sistematizar e praticar suas ações de gerencialmente cultural, é sugerida a instrumentalização de critérios simples de análise e prática no caminho de desvendamento das culturas de uma organização.

Dentro dessas premissas, um instrumento adequado às exigências de facilidade é a proposta de FLEURY (1996), que é baseada em cinco fases de encadeamento lógico e está totalmente centrada em critérios de entendimento da cultura que se articulam sob uma base sistêmica e contínua (Quadro 4).

Após o mapeamento cultural da organização, a implantação de um plano de gerenciamento ou de mudança da cultura organizacional de um hospital precisa ser entendida como o resultado da soma de vários esforços coletivos, apesar de engrendrado por uma gerência, o que reafirma a necessidade de comunicação para que haja a busca pelo aprendizado e o aprimoramento contínuo na prática de novos padrões de conduta.

\section{Quadro 4 - Metodologia propositiva de estudo da cultura hospitalar}

\begin{tabular}{|c|c|}
\hline $\begin{array}{l}\text { Histórico das } \\
\text { Organizações }\end{array}$ & $\begin{array}{l}\text { Recuperar o momento de criação da } \\
\text { organização e sua inserção no contexto } \\
\text { político e econômico: identificar o papel } \\
\text { do fundador, presidente ou diretores } \\
\text { que imprimiram a sua visão à organiza- } \\
\text { ção; e investigar os incidentes críticos } \\
\text { pelos quais passou a organização. Tais } \\
\text { investigações permitem o levantamento } \\
\text { das condições do ambiente em que a } \\
\text { organização está inserida. }\end{array}$ \\
\hline $\begin{array}{l}\text { Processo de socia- } \\
\text { lização dos novos } \\
\text { membros }\end{array}$ & $\begin{array}{l}\text { O momento de socialização é crucial } \\
\text { para a reprodução do universo simbó- } \\
\text { lico, pois os valores e comportamentos } \\
\text { vão sendo transmitidos e incorporados } \\
\text { pelos novos membros através de trei- } \\
\text { namentos e integração do indivíduo à } \\
\text { organização. }\end{array}$ \\
\hline $\begin{array}{l}\text { Políticas } \\
\text { de Recursos } \\
\text { Humanos }\end{array}$ & $\begin{array}{l}\text { As políticas de captação e desenvolvi- } \\
\text { mento de recursos humanos, em seus } \\
\text { processos de recrutamento, seleção, } \\
\text { treinamento e desenvolvimento, bem } \\
\text { como as políticas de remuneração e } \\
\text { carreira desempenham um papel funda- } \\
\text { mental no sentido de decifrar os padrões } \\
\text { culturais da organização. }\end{array}$ \\
\hline $\begin{array}{l}\text { Processos de } \\
\text { comunicaçãoo } \\
\text { e de decisão }\end{array}$ & $\begin{array}{l}\text { É preciso identificar tanto os meios } \\
\text { formais orais e escritos como os meios } \\
\text { informais. Tal exercício permite desven- } \\
\text { dar as relações entre categorias, grupos } \\
\text { e áreas da organização. }\end{array}$ \\
\hline $\begin{array}{l}\text { Organização } \\
\text { do processo } \\
\text { de trabalho }\end{array}$ & $\begin{array}{l}\text { É necessário investigar, no plano con- } \\
\text { creto de trabalho, como se efetivam as } \\
\text { relações entre os agentes, não bastando } \\
\text { uma análise superficial do organograma } \\
\text { hierárquico. A análise de como se orga- } \\
\text { niza o processo de trabalho permite a } \\
\text { identificação das categorias presentes } \\
\text { na relação de trabalho, subsidiando } \\
\text { ainda o mapeamento das relações de } \\
\text { poder existentes na organização. }\end{array}$ \\
\hline
\end{tabular}

Fonte: Elaboração própria. Adaptação baseada em FLEURY (1996).

Os esforços de ajustar a cultura organizacional aos objetivos de um melhor desempenho na organização fazse mister nas organizações hospitalares, porém deve-se ter claro que nem todas as políticas que tenham esse fim melhorarão a eficiência do ambiente. As práticas culturais institucionalizadas nas condutas dos agentes podem ser a maneira em que os profissionais ajustam-se em presença de distorções introduzidas por restrições institucionais, cuja modificação pode estar fora do alcance dos gerentes e diretores de hospitais. Algumas destas distorções podem encontra-se no desenho do sistema, nas normas relacionadas ao manejo dos recursos humanos e no grau de centralização das decisões.

É importante não perder de vista os efeitos sobre a eficiência, eficácia e eqüidade na hora de desenhar as políticas de gerenciamento e ajustamento da cultura organizacional, pois eliminar "desvios culturais" não é 
um fim em si mesmo, senão um meio através do qual se busca incrementar a produtividade e a qualidade dos serviços oferecidos pelas instituições de saúde, de forma que se possa alcançar melhores impactos no desempenho financeiro.

\section{Referências bibliográficas}

ABDALA, E. C.; SOUZA, D. A.; CASTRO, J. S.; et al.. A gestão orientada por processos: um estudo de caso em uma organização hospitalar brasileira. In: SIMPÓSIO DE EXCELÊNCIA EM GESTÃO E TECNOLOGIA, 3., 2006, Resende. Anais... Resende: AEDB, 2006.

BARLEY, S. R. Technology as an occasion for structuring: evidence from observations of CT scanners and the social order of Radiology Departments. Administrative Science Quarterly, v. 31, 1986.

BITTAR, O J. N. V. Indicadores de qualidade e quantidade em saúde. Revista de Administração em Saúde, v. 3, n. 12, 2001.

BORBA, G. S.; RODRIGUES, L. H. Pesquisa do conhecimento e Viabilidade da utilização de simulação computacional nos hospitais da região metropolitana de Porto Alegre. Revista Eletrônica de Administração - REAd, 1998.

CARAPINHEIRO, G. Saberes e poderes no hospital: uma sociologia dos serviços hospitalares. Porto: Edições Afrontamento, 1993.

CASAS, A. L. L. Qualidade Total em Serviços: conceitos, exercícios, casos práticos. São Paulo: Atlas, 1994.

CASTELAR, R. M; MORDELET, P.; GERABOIS, V. (Coord.) Gestão hospitalar: um desafio para o hospital brasileiro. Rennes, Editions ENPS, 1995.

CHERUBIN, A. U. Administração Hospitalar rumo ao $3^{\circ}$ milênio. Revista $\mathrm{O}$ mundo da Saúde, São Paulo, v.21, n.3, mai/jun. 1997.

FLEURY, M. T. O desvendar da cultura de uma organização: uma discussão metodológica. In: FLEURY, M. T.; FISCHER, R. M. Cultura e poder nas organizações. São Paulo: Editora Atlas, 1996.

KATZENBACH, J. R.; SMITH, D.K. A força e o poder das equipes. São Paulo: Editora Makron Books, 1994.

KOTTER, J.P.; HESKETT, J.L. A cultura corporativa e o desempenho empresarial. São Paulo: Editora Makron Books, 1994.

LANZER, E. A.; PEREIRA, M. F.; SILVEIRA, J. T. Dimensionamento de Eficiência Produtiva de Unidades Hospitalares Utilizando Análise de Envelopamento de Dados (DEA). Revista Brasileira de Administração Contemporânea, v.1, n.7, 1995.

LIMA-GONÇALVES, E. Condicionantes internos e externos da atividade do hospital-empresa. Revista de Administração de Empresas RAE eletrônica, São Paulo, v.1, n.2, 2002.
MACEDO, J. N. Cultura organizacional e gestão descentralizada do SUS. Revista Eletrônica de Administração - REAd, v.2 n.3, 1996.

MACHADO, V. B. \& KURCGANT, P. O processo de formação de cultura organizacional em um hospital filantrópico. Revista da Escola de Enfermagem da USP, v.38, n.3, 2004.

MAGALHÃES, E.; GOMES, L.; MAGALHÃES, E. Uma análise do processo de formulação e implementação de mudança organizacional: o caso de um instituto de previdência complementar e plano de saúde. In: SIMPÓSIO DE EXCELÊNCIA EM GESTÃO E TECNOLOGIA, 3., 2006, Resende. Anais... Resende: AEDB, 2006.

MARINHO, A. Estudo de eficiência em alguns hospitais públicos e privados com a geração de rankings. In: Textos para Discussão - IPEA, n. 794. Rio de Janeiro: IPEA, 2001.

MARTIN, J. Cultures in organizations - three perspectives. Oxford: Oxford University Press, 1992.

MINTZBER, H. The rise and fall of strategic planning. New York: Prentice-Hall, 1994.

MINTZBER, H. Structure et dinamique des organizations. Paris: Les Éditions d'organization, 1982.

MORGAN, G. Imagens da organização. São Paulo: Atlas, 1996.

NELSON, R. E. On the nonhierarchical nature of managerial hierarchies: formal structure, verbal networks, and culture in four hospitals. In: IBEROAMERICAN ACADEMY OF MANAGEMENT, São Paulo. Proceedings..., 2003.

PAIVA, W. P.; SAMPAIO, J. R. Cultura organizacional no setor de higiene e beleza: um estudo de caso. Revista Eletrônica de Administração - REAd, v.9, n.5, 2003.

PICCHIAI, D. Mudança em instituições hospitalares: análise do processo e estudo da ação do administrador hospitalar. Relatório NPP EAESP/FGV, n.4. São Paulo: FGV, 1998.

PIVETA, J. R. Cultura e aprendizagem organizacionais: um estudo de caso no segmento administrativo do hospital regional de Taguatinga-DF. 2004. Dissertação (Mestrado). UFSC: Florianópolis.

QUINN, J. B. Empresas muito mais inteligentes. São Paulo: Makron Books, 1996.

RIGOBEllO, L. M. M.; FORTUNA, C. M.; RIGOBELLO, L. X.; et al.. Processo de comunicação em grupos de aprendizagem: uma experiência multiprofissional. Revista latino-americana de enfermagem, v.6, n.4, 1998.

RODRIGUES FILHO, J. Método de pagamento hospitalar no Brasil. Revista de Administração Pública, Rio de Janeiro, n.24, ago-out., 1990.

ROSSI, P. S.; BATISTA, N. A. O ensino da comunicação na graduação em medicina - uma abordagem. Interface 
- Comunicação, Saúde e Educação, v.10, n.19, janjun. 2006.

SANTOS, E. G. Qualidade hospitalar e segurança para o paciente. Revista CQ-Qualidade, n.36, 1995.

SENGE, P.M., A quinta disciplina - arte, teoria e prática da organização de aprendizagem. São Paulo: Editora Best Seller, 1992.

SOUZA, L. E. M.; FOSSA, M. I. T. Comunicando com Relações Públicas - uma proposta de comunicação estratégica para o fortalecimento do comprometimento organizacional. UNIrevista, v. 1, n.3, 2006.
TAVARES, F. P. A cultura organizacional como instrumento de poder. Caderno de Pesquisas em Administração, v.1, n.3, 1996.

TODESCATI, E. R. Mudanças nas organizações. Florianópolis: UFSC, 1996.

TREVIZAN, M. A.; MENDES, I. A. C.; FÁVERO, N., et al.. Liderança e comunicação no cenário da gestão em enfermagem. Revista Latino-Americana de Enfermagem, v.6, n.5, 1998.

VASSALO, C. Por que os preços cobrados pelos hospitais brasileiros são tão altos? Revista Exame, n. 19, p.84-96, 1997.

\section{Sobre o autor}

\section{Elói Martins Senhoras}

Economista e cientista político, especialista pós-graduado em Administração: Gestão e Estratégia de Empresas. Foi professor visitante na University of Texas (UT) em Austin nos Estados Unidos e na Universidad de Buenos Aires na Argentina (UBA), e pesquisador visitante na University of British Columbia (UBC) e na University of Califórnia, Los Angeles (UCLA). Atualmente está finalizando os estudos de mestrado em Geografia na Universidade Estadual de Campinas (UNICAMP) e em Relações Internacionais na Universidade Estadual Paulista (UNESP). 